OPEN ACCESS

Edited by:

Philip P. Foster,

University of Texas Health Science Center at Houston, United States

Reviewed by:

Lucia Romo,

Université Paris Nanterre, France Caroline Payne-Purvis,

University of Florida, United States

*Correspondence:

Peter Payne

peter.payne@dartmouth.edu

Mardi Crane-Godreau

margaret.a.crane@dartmouth.edu

Specialty section:

This article was submitted to

Public Mental Health,

a section of the journal

Frontiers in Public Health

Received: 17 April 2018 Accepted: 12 September 2018

Published: 19 October 2018

Citation:

Payne P, Fiering S, Zava D, Gould TJ, Brown A, Hage P, Gaudet $C$ and Crane-Godreau M (2018) Digital Delivery of Meditative Movement

Training Improved Health of Cigarette-Smoke-Exposed Subjects.

Front. Public Health 6:282 doi: 10.3389/fpubh.2018.00282

\section{Digital Delivery of Meditative Movement Training Improved Health of Cigarette-Smoke-Exposed Subjects}

\author{
Peter Payne ${ }^{1 *}$, Steven Fiering ${ }^{1}$, David Zava ${ }^{2}$, Thomas J. Gould ${ }^{3}$, Anthony Brown ${ }^{4}$, \\ Paul Hage ${ }^{4}$, Carole Gaudet ${ }^{1}$ and Mardi Crane-Godreau ${ }^{1 *}$ \\ ${ }^{1}$ Department of Microbiology and Immunology, Geisel School of Medicine at Dartmouth, Lebanon, PA, United States, ${ }^{2}$ ZRT \\ Laboratory, Beaverton, OR, United States, ${ }^{3}$ Department of Biobehavioral Health, Pennsylvania State University, University \\ Park, PA, United States, ${ }^{4}$ Roswell Park Comprehensive Cancer Center, Buffalo, NY, United States
}

Many FA who flew prior to the ban on smoking in commercial aircraft exhibit an unusual pattern of long-term pulmonary dysfunction. This randomized controlled study tested the hypothesis that digitally delivered meditative movement (MM) training improves chronic obstructive pulmonary disease (COPD)-related symptoms in flight attendants (FA) who were exposed to second-hand cigarette smoke (SHCS) while flying. Phase I of this two-phase clinical trial was a single-arm non-randomized pilot study that developed and tested methods for MM intervention; we now report on Phase II, a randomized controlled trial comparing MM to a control group of similar FA receiving health education $(\mathrm{HE})$ videos. Primary outcomes were the 6-min walk test and blood levels of high sensitivity C-reactive protein (hs-CRP). Pulmonary, cardiovascular, autonomic and affective measures were also taken. There were significant improvements in the 6-min walk test, the Multidimensional Assessment of Interoceptive Awareness (MAIA) score, and the COPD Assessment Test. Non-significant trends were observed for increased dehydroepiandrosterone sulfate (DHEAS) levels, decreased anxiety scores and reduced blood hs-CRP levels, and increased peak expiratory flow (PEF). In a Survey Monkey questionnaire, $81 \%$ of participants who completed pre and post-testing expressed mild to strong positive opinions of the study contents, delivery, or impact, while $16 \%$ expressed mild negative opinions. Over the course of the year including the study, participant adoption of the MM practices showed a significant and moderately large correlation with overall health improvement; Pearson's $R=0.62, p<0.005$. These results support the hypothesized benefits of video-based MM training for this population. No adverse effects were reported.

Clinical Trial Registration: www.ClinicalTrials.gov, identifier: NCT02612389

Keywords: meditative movement, COPD, Qigong, flight attendants, digital training, interoception, video training, autonomic nervous system 


\section{INTRODUCTION AND BACKGROUND}

\section{Morbidities in Flight Attendants Exposed to Second-Hand Cigarette Smoke}

Flight attendants (FA) who flew before the ban on smoking in commercial aircraft (implemented progressively from 1988 to 2000) present with many of the co-morbidities of chronic obstructive pulmonary disease (COPD) but their pulmonary dysfunction differs from the standard definition of this disorder. These FA, in good health at the time that they were hired, were exposed to second-hand cigarette smoke (SHCS) in the course of their often vigorous work activities, as well as to a wide range of other stressors [including interpersonal stress, aviation-associated threats and emergencies, disrupted diurnal rhythms and polluted air (1-4)]. Recent studies of this population (5-8) demonstrate significant rates of abnormal pulmonary function: air trapping, reduced flow at mid-volume, reduced exercise tolerance and significantly elevated rates of chronic bronchitis and sinusitis. They also exhibit increased rates of cardiac disease, depression and anxiety (9), sleep disturbances, skin and reproductive cancers and hearing loss $(7,10)$. Many of these symptoms are also co-morbidities of $\operatorname{COPD}(11,12)$.

The magnitude and nature of these pulmonary abnormalities do not meet the standard criteria of COPD which is based on FEV1/FVC, the ratio of forced expiratory volume in $1 \mathrm{~s}$ (FEV1) to forced vital capacity (FVC) (12). The limitations of using the GOLD (12) standard defining COPD are increasingly recognized (13). Han et al. (14) have proposed that there is significant heterogeneity in the clinical symptoms of COPD and that a broader definition may be warranted to characterize its differing phenotypes. COPD is frequently characterized as being irreversible, yet these views generally predate current research that recognizes the heterogeneous nature of COPD (13) and the co-morbidity of post-traumatic stress disorder (PTSD) and COPD (or COPD-related symptoms) (15). Research into the effects of stress and trauma on pulmonary health, including insights into the embedding of fear responses by nicotine exposure, are changing the overarching paradigms about the nature of the lasting respiratory effects of tobacco smoke exposure (15-18).

\section{The Role of Cigarette Smoke (CS) in Disrupting Autonomic Nervous System (ANS) Function}

The role of FA is "to perform vital crewmember functions onboard air carrier aircraft, including emergency functions for aircraft evacuations, firefighting, first aid, and response to security threats" (19). Our work with this population of first responders has led us to examine the role of second hand cigarette smoke (SHCS) in autonomic nervous system (ANS) activation in this group. In addition to its role as a principal cause of COPD, cigarette smoke may contribute to mental health issues. Children (8-15 years old) exposed to secondhand smoke had higher rates of major depressive disorder and attention-deficit/hyperactivity disorder (20). Furthermore, there is a striking association between smoking and anxiety disorders, including PTSD (21).
In emergency workers, smoking after exposure to a disaster was associated with increased PTSD symptoms; the authors suggest that smoking-related dysregulation of the hypothalamicpituitary-adrenal axis contributes to increased PTSD symptoms (18). Studies in laboratory rodents show that nicotine is a causal agent of extended fear response. In mice, nicotine enhanced fear conditioning (22), delayed extinction of fear memories $(23,24)$, and disrupted safety learning $(17,25)$. While not directly tested, these effects of nicotine on fear learning and extinction could be related to altered hypothalamic-pituitaryadrenal function in those exposed to second hand smoke as well as active smokers. The resulting imbalance of the ANS may negatively impact the immune, cardiovascular, respiratory and musculoskeletal systems, and may reinforce the pathological changes triggered directly in the lungs by cigarette smoke (CS). This novel recognition of another mechanism for the negative effects of CS has not yet received the attention it deserves, and as far as we know, no therapeutic approaches specifically aimed at the autonomic effects of workplace exposure to SHCS have been proposed. Our selection of the meditative movement (MM) intervention and specific outcome measures are informed by the view that the autonomic effects of SHCS form a significant part of the lasting burden of exposure to SHCS.

\section{Qigong}

Qigong, a traditional Chinese health practice, encompasses a large range of practices using specific postures, movements, breathing patterns and visualizations to address disease patterns and improve health. It has been used in China for hundreds of years for people with respiratory, autonomic and immune dysfunction (26). Many of these practices have a broad positive influence on a range of pathologies $(27,28)$, and tend to restore physiological functions to normal range (29). Qigong, as well as Tai Chi and Hatha Yoga, have been proposed to constitute a novel category of exercise, "meditative movement" (MM) (30). Specific MM practices have been shown to be an effective intervention for COPD (31-34) and to be equivalent or superior to conventional pulmonary rehabilitation in benefiting several of its symptoms $(35,36)$. MM has demonstrated benefits for the immune system, both reducing chronic systemic inflammation $(37,38)$ and increasing the effectiveness of acquired immune response to infection (39). MM practices help restore functionality to the ANS (40-43), and also may reduce depression and anxiety (38) and improve quality of life in many chronic diseases $(44,45)$. MM also induces positive states of mind through focusing awareness on interoceptive and proprioceptive experiences (46).

\section{Interoception}

Interoception is the perception of the internal state of the body, and is recognized as important for emotional and physiological self-regulation $(47,48)$. Autonomic nerve pathways from the viscera link to the hypothalamus and to the insular cortex, facilitating physiological and affective homeostasis. Adequate interoceptive function is thus important for autonomic function as well as a sense of well-being. MM directly addresses interoceptive ability, and this may be one of the mechanisms for MM's beneficial effects on the ANS, immune system, and other 
physiological systems (48-50). We believe MM could prove to be of specific benefit to the particular problems experienced by FA exposed to SHCS, especially in view of the possible linking factor of autonomic imbalance.

\section{Aim}

Our aim was to determine the effectiveness of a digitally delivered MM training, as compared to a control group that received health education videos, by pre-intervention and postintervention testing of pulmonary, autonomic, interoceptive, and immune function in a cohort of FA who were previously exposed to occupational SHCS. We sought to determine whether this specifically adapted MM training can be effectively delivered digitally, providing the benefits of $\mathrm{MM}$ without face-to-face instruction.

\section{METHODS}

The present paper details Phase II of a 2-Phase study. This followed Phase I, a single-arm non-randomized pilot study in which we developed and tested methods for MM intervention using face-to-face classroom instruction. The full protocol and results from Phase I have been published (51). Phase II is a randomized controlled trial comparing $\mathrm{MM}$ delivered by video only, to a health education (HE) intervention. This study was approved by Dartmouth College IRB (CPHS \#28572). Both phases of the study are registered at Clinical Trials.gov under the code: https://clinicaltrials.gov/ct2/show/NCT02612389/. As approved by the Dartmouth CPHS, all participants gave written consent using IRB-approved informed consent forms (52) when they enrolled in the study. Participants were assigned alphanumeric code numbers to provide anonymity and protect the privacy of study volunteers.

\section{Participants \\ Recruitment}

Fifty-one FA were recruited from throughout the continental US, in particular the Northeast and areas around Atlanta GA, Miami FL, San Francisco CA, Seattle WA, and Portland, OR. Primary outreach was through the networks of FA that we had already established in Phase I, as well as through existing flight attendant organizations, social media, flight attendant publications. Our collaborators at Harvard School of Public Health also provided support. Social media support was provided by the Department of Health Behavior at the Roswell Park Cancer Institute in Buffalo, NY.

\section{Inclusion and Exclusion Criteria}

All participants were required to be non-smoking former or current flight attendants, who had been exposed to SHCS for at least 5 years while flying. In addition, participants were required to have devices for accessing audio and video content and instruction, and to be willing to use them. Pregnancy or planned pregnancy, as well as cognitive impairment, severe emotional problems, or physical inability to perform the exercises, were grounds for exclusion. Participants were asked not to modify their lifestyle significantly during the study period apart from the practice required by the study. Since each participant acted as his/her own control, we did not exclude participation on the basis of medication use.

\section{Randomization and Controls}

In this randomized controlled trial (RCT), participants were stratified by region and randomized to the intervention group or to the control group, using the covariate adaptive randomization method (CARM) (53). CARM was used because it accommodates recruiting and testing over an extended timeframe. Volunteers assigned to the MM interventional group received weekly assignment with specific MM training videos. The control group received health education (HE) videos. Blinding participants to the intervention was not practicable. Tests were scored by assistants who were blinded to the assignment of study participants.

\section{Intervention}

\section{Experimental Design}

In Figure 1, experimental design for this study is shown. Following recruitment, enrolling, and consenting, preintervention testing was administered at locations throughout the country convenient to participants. Over a 2-h period, participants completed the questionnaires, cardiovascular measures were taken, and various tests were administered as described below.

Participants were then randomized to a MM intervention group or a control group receiving HE videos, which were selected Ted Talks available through YouTube. Over $\sim 4$ months, participants were assigned $\sim 10 \mathrm{~h}$ of video instruction in MM exercises. Exercise selection was based on experience from Phase I. The video assignments were sent out each week via email with instructions to watch and review selected videos online. The control group also received an email each week assigning a $\mathrm{HE}$ video. HE videos dealt with general health questions, but did not contain instructions on any form of practice. Both groups were also completed weekly Survey Monkey questionnaires about their weekly participation. After the training period, the same tests were administered, and the data was analyzed.

At the conclusion, the participants in the control group were offered the opportunity to engage the MM training by viewing the MM videos, with the same weekly structure as was used for the intervention group. After this group had completed their training, all those who received the MM videos, including intervention and control group participants, were asked to complete a Survey Monkey questionnaire evaluating the training; and 6 months after the conclusion of training, all participants were asked to complete a second survey about changes in physical and affective health over the previous year.

\section{Implementation of Intervention}

The MM instructional videos developed for the Phase II MM intervention were based on our work in Phase I (51), in which we determined the most appropriate practices for this population of FA. These included simple postural practices, such as standing and sitting, moving practices, such as walking, and simple breathing practices. The practices involved static postures or 


\section{Timeline}

Oct 2015-

Mar 2016

Mar-Apr

2016

$$
\text { (2) }
$$

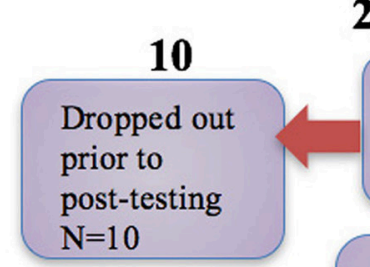

26

26 control group

51

51

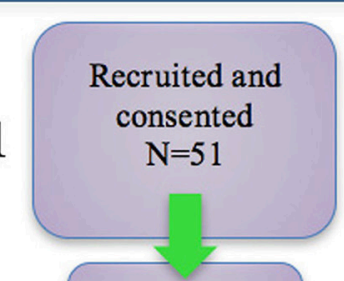

Pre-testing $\mathrm{N}=51$

\section{5}

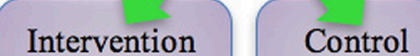

Group Group

$\mathrm{N}=26 \longrightarrow \mathrm{N}=25$
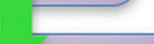

12 Weeks

of $\mathrm{HE}$

videos

$\mathrm{N}=21 \quad 21$

\section{6}

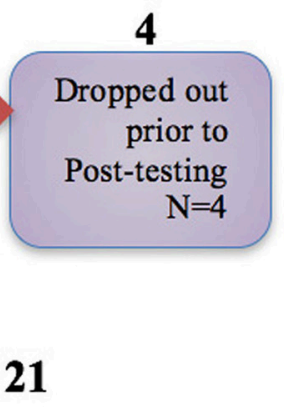

Aug-Sep

2016

37 Post-testing

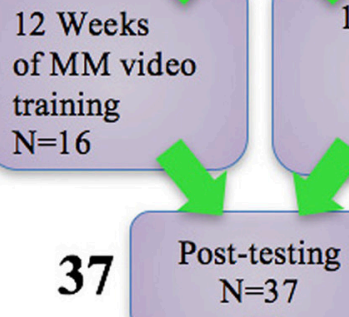

Sep 2016
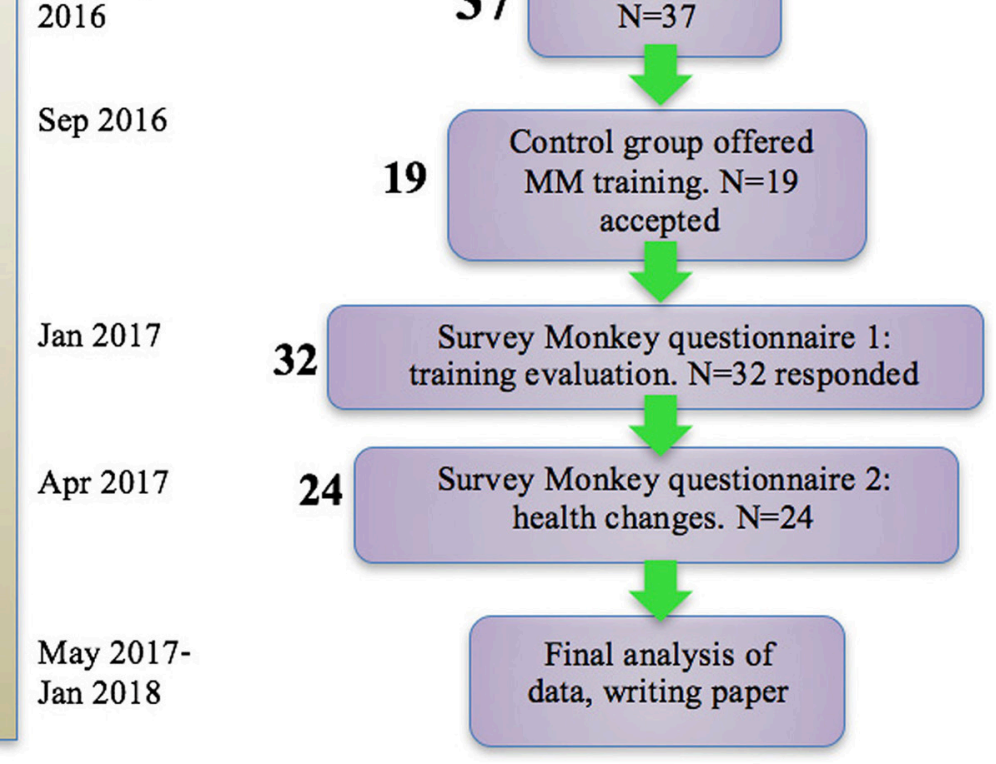

FIGURE 1 | Participant flow and timeline. After recruiting and pre-testing, participants were randomized to intervention and control groups. Following the training period, participants were tested again, and the control group participants were offered the opportunity to receive the same MM training. After all participants had completed the training, two final questionnaires were administered. Dropouts and numbers responding to questionnaires are shown.

slow and gentle movement. Participants were asked to direct their attention to environmental, interoceptive and kinesthetic awareness, and to focus on specific mental images. One advantage of this form of practice is that it can easily be integrated into daily life, thus making minimal time demands, and participants were instructed to implement this integration. Figure 2 shows one of 


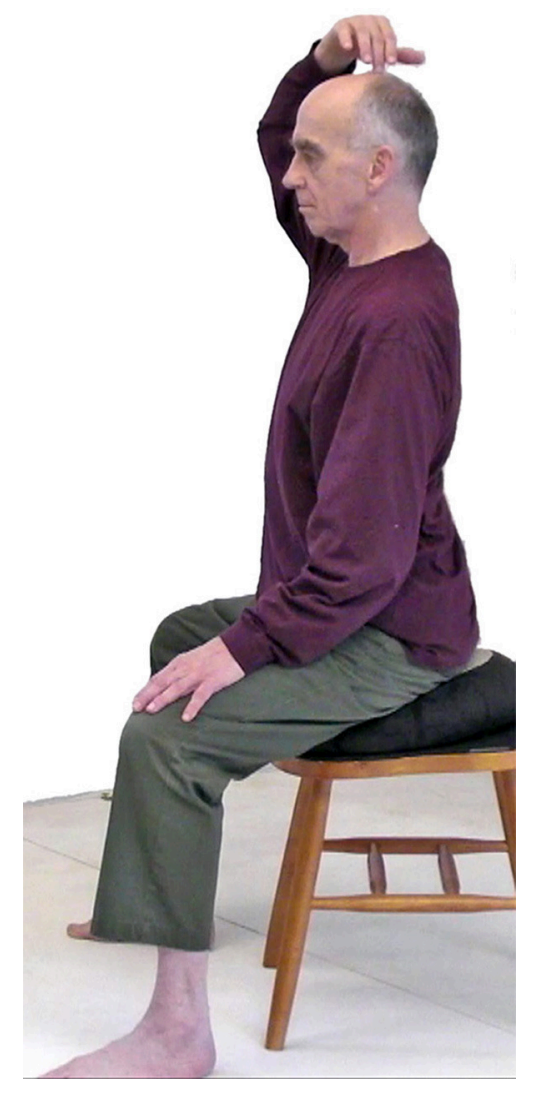

FIGURE 2 | A typical MM practice. One of the authors demonstrating an MM exercise, showing how to sense correct alignment with gravity while seated.

the authors (PP) demonstrating a practice of awareness of balance while sitting. Access to the videos is available (54-56).

The videos used for the control group were Ted Talks available on YouTube, pertaining to general health and not including the teaching or encouragement of specific health practices. Each week all participants received an email asking them to view specific videos; the MM videos were distributed to participants either via links to Vimeo files or by mailed DVDs, depending on the preference of participants; and the control group participants were provided with links to health education Ted talks on YouTube.

Each week study participants were sent Survey Monkey questionnaires with follow-up emails or phone calls if participants did not respond. In the questionnaires they were asked to report on levels of participation and provide feedback on their experiences while doing the MM practices. Feedback was regularly reviewed to evaluate the use, compliance and acceptability of each of the practices.

Harmful side effects are very rare in the practice of MM (57), but participants were instructed to immediately discontinue the exercises in case they should experience dizziness, rapid or irregular heart-beat, chest pain, pressure in the head or headache, significant pain anywhere in the body or sudden or excessive dyspnea.

\section{Outcome Measures}

\section{Primary Outcome Measures}

The guidelines of the American Thoracic Society (ATS) were followed when conducting the six-minute walk test (6MWT). These tests were conducted on a level indoor surface, free of obstructions. Trained research technicians were present to assist with any difficulties experienced by participants. The distance walked in $6 \mathrm{~min}$ by each participant was measured and recorded (58-61).

Blood samples were obtained to measure High Sensitivity C-reactive protein (hs-CRP), a useful marker for systemic inflammation (62). This was obtained by finger-stick blood draw method, collected onto a prepared blood card. After allowing the blood spots to dry overnight the filter cards were stored frozen until they were shipped to ZRT Laboratory where they were analyzed by immunoassay as previously described (63).

\section{Secondary Outcome Measures}

Blood pressure was recorded in a seated position from the dominant arm, after the participant had been at the testing center for over $30 \mathrm{~min}$. At least two readings were taken, $2 \mathrm{~min}$ apart, and if the readings differed by more than 10 points, a third reading was taken and the average value obtained and recorded.

The COPD Assessment Test (CATest) $(64,65)$, a short questionnaire used to evaluate the perceived impact of respiratory dysfunction, was utilized.

Spirometry was performed according to the ATS guidelines (66) using specific validated spirometric cut points (67). Standard measures recorded were FEV1 (forced expiratory volume in $1 \mathrm{~s})$, FVC (forced vital capacity), forced expiratory flow between 25 and $75 \%$ of capacity (FEF 25-75), peak expiratory flow (PEF) and flow/volume curves, using the EasyOne Plus Frontline spirometry system (ndd Medical Technologies, Andover, MA).

To detect symptoms of autonomic dysfunction, subjects completed the self-report COMPASS 31 (68).

The Zung Self-Rating Depression and Anxiety Scales (selfreport instruments) were employed $(69,70)$. Subjects completed these questionnaires in the presence of a research team member.

Subjects completed the Multidimensional Assessment of Interoceptive Awareness (MAIA) (71). The degree of awareness of interoceptive cues, and the level of comfort with these interoceptive cues are evaluated by the MAIA. The ten different dimensions measured include: Noticing, Not Distracting, Not Worrying, Attention Regulation, Emotional Awareness, Self Regulation, Body Listening and Trusting.

Blood samples were obtained using finger-stick procedure, and analyzed at ZRT Labs, Beaverton, Oregon, as described in Payne et al. (51). Diurnal urine and saliva samples were also collected. Subjects were given collection kits and instructed in their use, and mailed the samples to the researchers. Samples were stored at $-80^{\circ} \mathrm{C}$ and sent in batches to ZRT Lab for analysis by mass spectrometry. For a full listing of biomarkers tested, see our earlier protocol paper (51).

\section{FA survey monkey questionnaires}

Participants in the MM study were surveyed weekly to determine the level of participation and follow through with assigned 


\section{Average question responses by subject}

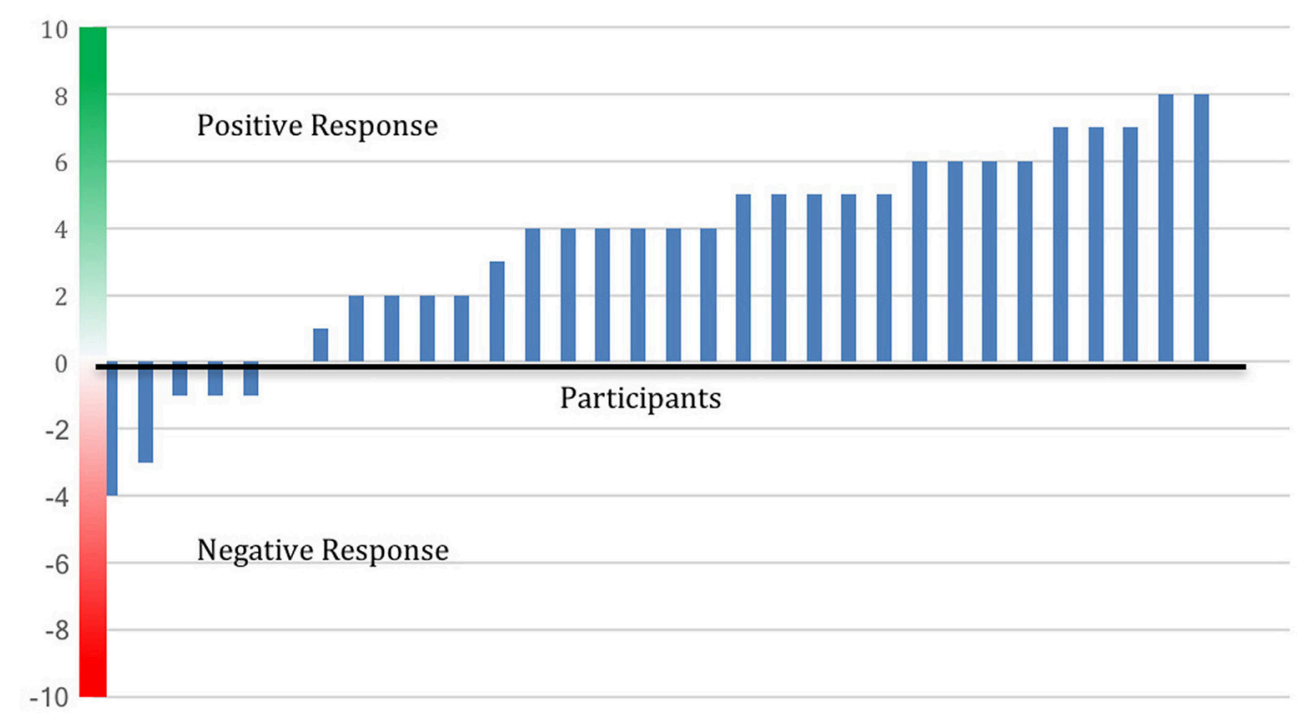

FIGURE 3 | Positive evaluation of training by $81 \%$ of participants. Average response to the Survey Monkey questions is shown by participant. Out of 32 respondents (16 from the MM group and 16 from the control group who opted to receive the MM training), 26 made an average positive evaluation. Distance above the $x$-axis indicates degree of positive response, below the $x$-axis indicates negative response.

videos. Non-compliant subjects were reminded first by email and then by phone calls. Participants in the control group were also surveyed and followed on a weekly basis.

In addition to the weekly progress reports, participants were asked to complete two questionnaires. Survey Monkey questionnaire 1: participants who had received the MM training videos (including both those in the initial MM intervention and those in the control group who chose to receive the videos after completion of Phase II) were asked the following five questions about their response to the videos, via a Survey Monkey questionnaire. All respondents were included in the subsequent data analysis.

1: Please give general comments on the practice.

2: Please critique the video presentation.

3: Are you willing to continue participating in studies of MM?

4: Are you finding that you are more aware of your body after participating in the training?

5: Do you feel more able to cope with stress after this training?

Each response was scored by a neutral blinded third party as very positive, positive, neutral, negative, and very negative, using numbers from 2 to -2 , and the scores summed for each participant.

The second Survey Monkey questionnaire was administered 6 months after completion of the training. All participants who had received the training videos were asked via Survey Monkey about their continuing practice of the various exercises, rating each of 14 exercises as "not doing it," "doing occasionally," or "doing 3 times a week or more." In addition, participants were asked about their health changes over the prior year. Each of 11 physical health symptoms (sleep quality, balance, endurance, breathlessness, joint pain, digestion, respiratory infections, dry mouth, cardiovascular disorders, blood pressure, overall health) and four affect-related items (mood, security, happiness, dealing with stress) were rated as "never a problem," "worse compared to a year ago," "about the same as a year ago," or "improved compared to a year ago."

\section{Statistical Methods and Scoring}

We determined the required sample size for statistical significance based on a predicted difference of 46 meters in the 6MWT and an assessment of previous similar studies. Using this criterion, 20 participants in each group were needed to achieve a statistical power of $80 \%$ at a significance level of $5 \%$. To compensate for anticipated drop-out, we recruited a total of 51 participants. Descriptive statistics, including mean, percent change, correlation coefficients, and $p$-values, were used to describe and summarize data. In cases where data for a subject on one outcome measure is missing, we have chosen to eliminate that subject from the calculations for that measure. Significance levels for changes in measures from pre- to post-intervention test of the MM group as compared with the control group were determined using ANOVA. $P<0.05$ was selected as the threshold for significance. Raw data and statistical calculations made are available.

The results from the Survey Monkey questionnaires were treated as categorical data. In Survey Monkey questionnaire 1, each response was scored by a neutral third party as very positive, positive, neutral, negative, and very negative using numbers from 2 to -2 , and the scores summed. In the question about willingness to continue, a "yes" was scored as +2 , a "no" as -2 , and a "don't know" as zero. Possible total scores for the five 
questions ranged from 10 to -10 . These results are presented in a bar graph without the use of $p$-values as these were not deemed necessary.

In Survey Monkey questionnaire 2, for the health portion, responses of "never a problem" and "about the same as a year ago" were assigned a value of zero; "worse compared to a year ago" was scored as negative 2; and "improved compared to a year ago" was scored as positive 2 . Scores for each person were summed in an affective health change score, a physical health change score, and a total health change score. In the exercise adoption portion, we wished the total score to reflect the amount of time each participant spent per week on practice. Therefore, we scored "not doing it" as zero, "doing occasionally" as 1, and "doing 3 times a week or more" as ten. Exercise adoption scores were summed for each person, and Pearson's R correlation coefficients, and $p$-values were determined.

\section{RESULTS}

\section{Participants}

\section{Participant Flow}

Figure 1 above shows numbers of participants recruited and consented, number of drop-outs, and numbers completing the study. Fifty-one flight attendants met the inclusion criteria and were recruited and consented. They were then stratified by geographic area and randomized to an MM intervention group $(N=25)$ and a health education control group $(N=26)$. The two groups began receiving the appropriate videos as well as regular Survey Monkey questionnaires. Prior to the completion of the post-intervention testing, 10 participants in the MM group and 4 in the control group discontinued the study due to stated lifestyle conflicts. Sixteen completed the MM portion and 21 completed the control portion for a total of 37 . When offered the opportunity to receive the MM training after the completion of post-testing, 19 participants from the control group opted to do so, and over the following 4 months received the same sequence of MM training videos as was used in the main intervention. Two final Survey Monkey questionnaires were sent to all those who had received the training. Results were then analyzed.

\section{Baseline Clinical Characteristics and Demographics}

The characteristics of the 51 consented and pre-tested recruits are shown in Table 1. While every effort was made to reach out to a diverse population, all of those consented for this study were female and White. This lack of diversity is consistent with the findings of McNeely (72) who reported that only $11.5 \%$ of former or current flight attendants between the ages of 50 and 90 are non-White. McNeely also reported that $87 \%$ of US flight attendants between 50 and 90 are female (72). This helps to explain the low level of diversity within the study population.

Baseline clinical characteristics of the two groups differed substantially. Due to random variation, the control group was healthier than the intervention group on almost all health-related measures. The control group scored more than 5\% lower on the CATest, Zung Anxiety, Zung Depression, COMPASS 31, hsCRP (all indications of better health); and had higher scores on the MAIA (especially body listening) and higher blood levels of
TABLE 1 | Baseline characteristics of subjects who completed the pre-testing phase of the study.

\begin{tabular}{lccc}
\hline & $\begin{array}{c}\text { MM } \\
\text { Intervention }\end{array}$ & $\begin{array}{c}\text { Control } \\
\text { group }\end{array}$ & $\begin{array}{c}\text { Dropouts or } \\
\text { did not complete } \\
\text { post-testing }\end{array}$ \\
\hline $\begin{array}{l}\text { Total randomized } \\
\text { (completed pre-testing) }\end{array}$ & 26 & 25 & n.a. \\
Numbers in each group & 16 & 21 & 14 \\
Female & $100 \%$ & $100 \%$ & $100 \%$ \\
Average age & 68 & 68 & 67 \\
Age range & $62-74$ & $55-79$ & $51-79$ \\
Body mass index average & 24.3 & 24.6 & 25 \\
BMl range & $18.5-33.7$ & $20-29.7$ & $17.1-30.7$ \\
White & 16 & 21 & 14 \\
African-American & 0 & 0 & 0 \\
Hispanic & 0 & 0 & 0 \\
\hline
\end{tabular}

51 subjects were consented and tested at the beginning of the study, and of these, 37 completed the study.

testosterone and DHEAS. The only measure possibly indicative of lower health levels in the control group were lower melatonin levels. This data appears in Table 2.

\section{Adverse Events}

Reports of adverse side effects from MM are rare (57). Consistent with this, no adverse events were reported by any participant enrolled in this study.

\section{Outcome Measures}

\section{Detailed Results of Pre-post Testing}

Results are shown in Table 3. Analysis of variance (ANOVA) revealed statistically significant improvements in the MM group compared to the control group, of the 6MWT, the MAIA score, and the CATest, indicating improved endurance, interoceptive awareness, and pulmonary function. All the MAIA sub-scores improved substantially ( $+10 \%$ or above) compared to the control group, with the exception of Noticing and Emotional Awareness; there were no substantial increases in MAIA sub-scores in the control group. However, only the $26 \%$ increase in the MM group of Self-Regulation reached significance $(p<0.05)$. A large increase in DHEAS levels in the MM group as compared to the control group almost reached stated significance $(p=0.0566)$. Among the changes not reaching statistical significance were: a substantial (29\%) reduction in hs-CRP in the MM group compared to a slight (6\%) decrease in the control group; the COMPASS 31, a measure of autonomic dysregulation, increased by $7 \%$ in the control group (indicating increased autonomic dysregulation), and decreased by $9 \%$ in the MM group; and the Zung Anxiety score fell by $10 \%$ in the MM group and by $4 \%$ in the control group. There was also a non-significant slightly reduced resting heart rate in the MM group as compared to the control group, and slightly increased peak expiratory flow (PEF) in the MM group coupled with slightly decreased PEF in the control group. There was a large increase in blood testosterone levels in both groups. 
TABLE 2 | Baseline clinical characteristics.

\begin{tabular}{|c|c|c|c|c|}
\hline Measure & MM & Control & $\begin{array}{l}\text { Control } \\
\text { minus } \\
\text { MM }\end{array}$ & $\begin{array}{l}\text { Control } \\
\text { minus } \\
\text { MM \% }\end{array}$ \\
\hline COPD-short & 8.88 & 7.24 & -1.64 & $-18 \%$ \\
\hline FEV1 & 90.25 & 89.38 & -0.87 & $-1 \%$ \\
\hline FVC & 89.44 & 89.95 & 0.51 & $1 \%$ \\
\hline FEV1/FVC & 100.50 & 99.05 & -1.45 & $-1 \%$ \\
\hline FEF 25-75 & 91.88 & 90.24 & -1.64 & $-2 \%$ \\
\hline PEF & 95.69 & 97.76 & 2.07 & $2 \%$ \\
\hline Zung anxiety & 32.94 & 31.20 & -1.74 & $-5 \%$ \\
\hline Zung depression & 36.63 & 34.70 & -1.93 & $-5 \%$ \\
\hline COMPASS31 & 16.81 & 14.05 & -2.76 & $-16 \%$ \\
\hline MAIA: overall & 21.22 & 26.75 & 5.53 & $26 \%$ \\
\hline Noticing & 2.77 & 3.45 & 0.68 & $25 \%$ \\
\hline Not distracting & 2.20 & 2.45 & 0.25 & $11 \%$ \\
\hline Not worrying & 2.87 & 3.00 & 0.13 & $5 \%$ \\
\hline Attention regulation & 2.64 & 3.25 & 0.62 & $23 \%$ \\
\hline Emotional awareness & 3.47 & 3.98 & 0.51 & $15 \%$ \\
\hline Self regulation & 2.97 & 3.53 & 0.56 & $19 \%$ \\
\hline Body listening & 2.20 & 3.17 & 0.97 & $44 \%$ \\
\hline Trusting & 3.49 & 4.10 & 0.61 & $18 \%$ \\
\hline 6MWT-meters & 538.90 & 546.90 & 8.00 & $1 \%$ \\
\hline Blood pressure: diastolic & 76.56 & 79.76 & 3.20 & $4 \%$ \\
\hline Systolic & 123.31 & 124.33 & 1.02 & $1 \%$ \\
\hline Resting heart rate & 67.31 & 67.90 & 0.59 & $1 \%$ \\
\hline hs-CRP & 1.63 & 1.52 & -0.11 & $-7 \%$ \\
\hline Testosterone & 16.93 & 21.10 & 4.17 & $25 \%$ \\
\hline DHEAS & 2.13 & 3.68 & 1.55 & $73 \%$ \\
\hline 1st AM urine cortisol & 29.85 & 43.05 & 13.21 & $44 \%$ \\
\hline 1st AM urine melatonin & 25.31 & 22.05 & -3.26 & $-13 \%$ \\
\hline
\end{tabular}

The right column shows the percentage difference between the intervention and control groups average value at baseline. Green boxes indicate measures possibly indicative of better health; red boxes indicate potential indicators of worse health.

\section{Survey Monkey Questionnaire 1}

After all training was completed (Jan 2017), the 35 participants who had received the MM video training (including 16 in the initial MM intervention and 19 in the control group who chose to receive the videos after completion of post-testing) were asked the following five questions about their response to the videos, via a Survey Monkey questionnaire. Thirty-two participants responded to the questionnaire.

1: Please give general comments on the practice.

2: Please critique the video presentation.

3: Are you willing to continue participating in studies of MM?

4: Are you more aware of your body after participating in the training?

5: Do you feel more able to cope with stress after this training?

As described under section Statistical Methods and Scoring, above, each response was scored by a neutral blinded third party.

Figure 3 shows degree of positive rating from each participant; $81 \%$ of participants rated the overall experience positively. Average scores for each question are shown in
TABLE 3 | Outcome measures.

\begin{tabular}{|c|c|c|c|c|}
\hline \multicolumn{2}{|c|}{ Outcome measure } & \multirow{2}{*}{$\begin{array}{c}\% \text { Change in } \\
\text { MM group } \\
+7\end{array}$} & \multirow{2}{*}{$\begin{array}{c}\begin{array}{c}p \text {-value } \\
\text { (ANOVA) }\end{array} \\
p<0.005^{\star \star}\end{array}$} & \multirow{2}{*}{$\begin{array}{c}\begin{array}{c}\% \text { Change in } \\
\text { HE group }\end{array} \\
-2\end{array}$} \\
\hline Primary & $6 \mathrm{MWT}$ & & & \\
\hline & hs-CRP & -29 & $p=0.76 \mathrm{~ns}$ & -6 \\
\hline \multirow[t]{4}{*}{ Cardiovascular } & Avg systolic BP & 0 & ns & 2 \\
\hline & Avg diastolic BP & 2 & ns & -3 \\
\hline & Resting HR & -4 & $p=0.6 \mathrm{~ns}$ & 0 \\
\hline & $\begin{array}{l}\% \text { Change HR } \\
\text { after } 6 \mathrm{MWT}\end{array}$ & 18 & $p=0.1$ & -18 \\
\hline \multirow[t]{5}{*}{ Pulmonary } & CATest score & -32 & $<0.01^{*}$ & +12 \\
\hline & FEV1 & 0 & ns & -1 \\
\hline & FVC & 0 & ns & -1 \\
\hline & FEF 25-75 & -1 & ns & -3 \\
\hline & PEF & +2 & ns & -2 \\
\hline Autonomic & Compass 31 & -9 & $p=0.1117$ & +7 \\
\hline \multirow[t]{3}{*}{ Humoral } & Vit D level & -2 & ns & 4 \\
\hline & Testosterone & +44 & ns & +41 \\
\hline & DHEAS & 42 & $p=0.0566^{\diamond}$ & -10 \\
\hline \multirow[t]{9}{*}{ Interoceptive } & MAIA & 24 & $p<0.005^{\star \star}$ & -1 \\
\hline & Noticing & 9 & ns & 6 \\
\hline & Not distracting & 13 & $p \sim 0.1$ & -16 \\
\hline & Not worrying & 11 & $p \sim 0.1$ & -4 \\
\hline & $\begin{array}{l}\text { Attention } \\
\text { regulation }\end{array}$ & 14 & ns & 4 \\
\hline & $\begin{array}{l}\text { Emotional } \\
\text { awareness }\end{array}$ & 7 & ns & 2 \\
\hline & Self regulation & 26 & $p<0.05^{\star}$ & 2 \\
\hline & Body listening & 28 & $p \sim 0.1$ & -7 \\
\hline & Trusting & 21 & $p \sim 0.1$ & 6 \\
\hline \multirow[t]{2}{*}{ Affective } & Zung anxiety & -10 & $p=0.234 \mathrm{~ns}$ & -4 \\
\hline & Zung depression & -8 & ns & -8 \\
\hline
\end{tabular}

Percent change in values for the intervention group and for the control group are shown as well as $p$-values determined by ANOVA. Full pre- and post-test values are available as Supplementary Materials. ${ }^{* *}, \leq 0.01$ significance level; ${ }^{*}, \leq 0.05$ significance level; +, trending; ${ }^{\triangleright}$, almost significant; $n s$, not significant.

Figure 4. Scores for each of the five questions could range from 2 to -2 . Not all participants responded to all questions. We note that numerous participants remarked on increased stress resilience and positive body awareness, which appears to be reflected in the increased MAIA sub-scores of Self-Regulation $(+26 \%)$ and Body Listening $(+26 \%)$.

\section{Survey Monkey Questionnaire 2}

Six months (Sept 2017) after the completion of training, participants were again surveyed to determine if there were perceived changes in health or wellbeing. As described above in section Statistical Methods and Scoring, the "Health: Physical" and "Health: Affective" portions were scored separately and also combined for a total health change score. Scores for each person reflected the change of their level of health since 1 year ago, and were therefore roughly reflective of health change over the duration of the study. Exercise scores were indicative of the degree to which the subject adopted the MM practice and continued beyond the end of the study. All of those answering 


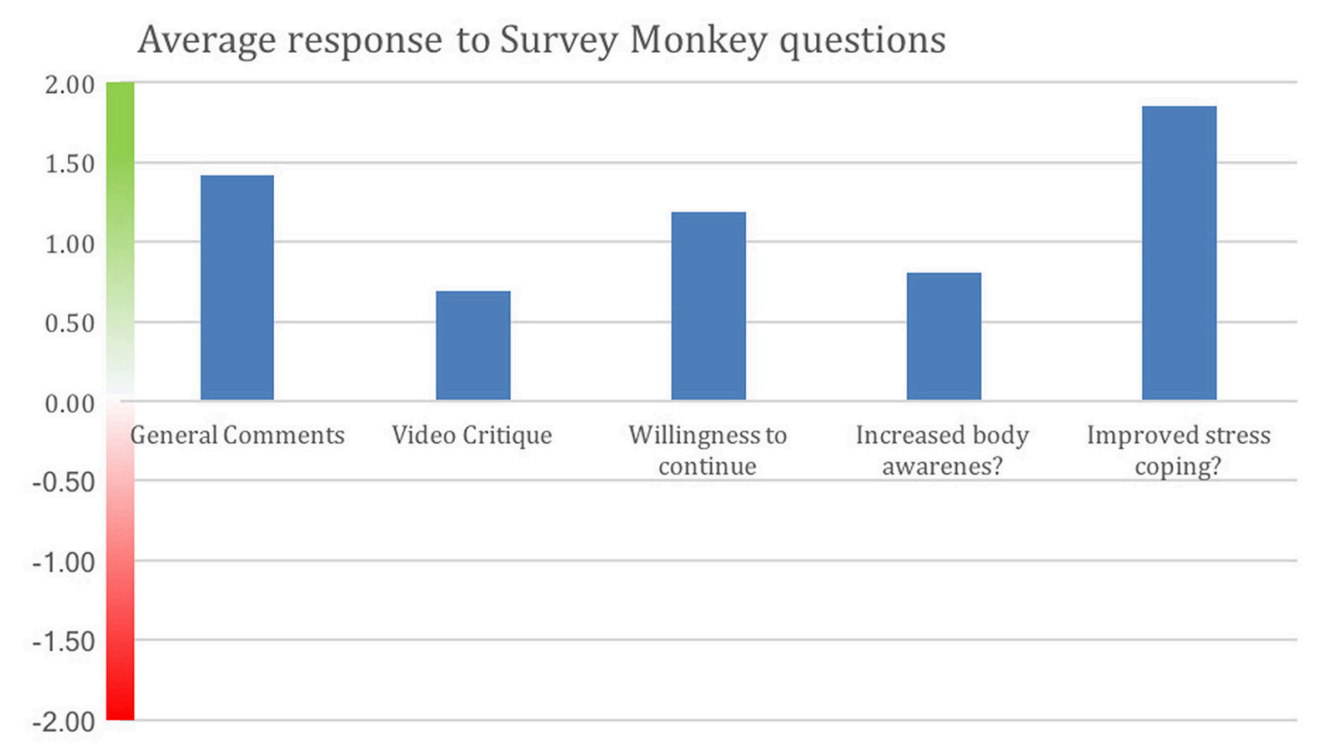

FIGURE 4 | Positive average response by all participants to each Survey Monkey question. Improved stress coping received the strongest positive response. Y-axis indicates degree of negative or positive responses. 16 of the MM intervention participants and 16 from the control group who opted to do the MM training responded. Not all participants answered all questions.

had received all the MM video materials and instructions at some time during the study. We excluded those who experienced a major health crisis, such as major surgery or severe illness, over that period of time, on the grounds that these events induce disturbance that is not relevant to, and obscures, the factors of the study. Twenty-four respondents are included in the analysis, 12 from the intervention group and 12 from the control group who opted to do the MM training.

Figure 5 shows the results in graphical form, and Table 4 shows correlation and significance. Pearson's correlation analysis shows moderate and significant positive correlations, indicating that the amount of variance in year-to-year health change attributable to interaction between the variables is approximately one-third. The correlation to the physical health score is distinctly greater than to the affective score.

\section{Graphical Summaries of Key Results}

Key results of the study are summarized in graphical form in Figures 6-11. These figures reflect changes in test results measured before and after the MM intervention.

\section{DISCUSSION}

\section{Summary}

Our results demonstrate improved exercise tolerance and endurance, reduced COPD-related symptoms, and improved interoception, especially in the ability to handle stress. This supports our hypothesis that video-delivered MM training can produce similar health benefits to those found in Phase I with inperson instruction. Phase I results had shown clinically relevant and statistically significant improvements in the 6MWT, hsCRP, systolic BP, resting HR, COMPASS31, MAIA, and Zung
Anxiety Inventory, as well as clinically significant improvement in the CATest. In Phase II, the COMPASS 31 (a measure of autonomic function), hs-CRP (a biomarker of systemic inflammation), resting heart rate, and anxiety, all showed substantial improvement in the same direction as found in the Phase 1 study, but without reaching statistical significance. The changes in symptoms of dyspnea, as well as improved endurance demonstrated by the 6MWT results, support our hypothesis that MM practice can improve pulmonary health. These results are in line with other studies of the effects of MM, specifically on respiratory disease (33) as well as on other health issues (37). Reduced exercise endurance (as measured by the 6MWT) is a strong risk factor and co-morbidity for a variety of pathologies, especially in the elderly, suggesting that MM practice may have preventive and ameliorative health effects in FA exposed to SHCS and possibly in other populations.

\section{Outcomes}

Pre and post-intervention testing showed that the MM intervention was effective and that it significantly changed results of the 6MWT, one of the primary outcomes. The MM intervention training contained no form of resistance training or aerobic exercise and the underlying physiological mechanisms of these changes remain uncertain. We have speculated that they are due to changes in the autonomic nervous system. In the current study, autonomic function, as measured by COMPASS 31, showed improvement in the MM interventional group, while scores in the control group indicted poorer autonomic function (as was reported in Phase I) although this did not reach statistical significance. We note that in both this study and in Phase 1 there was a small increase in peak expiratory flow (PEF); this did not approach significance, but we speculate that 


\begin{tabular}{|c|c|c|c|}
\hline \multicolumn{3}{|c|}{$\begin{array}{l}\text { Health change } \\
\text { over past year }\end{array}$} & \multirow[t]{2}{*}{$\begin{array}{c}\text { Exercise } \\
\text { Adoption } \\
\text { Score } \\
\end{array}$} \\
\hline $\begin{array}{l}\text { Affect } \\
\text { score }\end{array}$ & Physical Score & Total Score & \\
\hline 2 & 6 & 8 & 68 \\
\hline 4 & 8 & 12 & 67 \\
\hline-2 & 4 & 2 & 66 \\
\hline 8 & 2 & 10 & 63 \\
\hline 8 & 10 & 18 & 59 \\
\hline 6 & 8 & 14 & 57 \\
\hline 0 & -2 & -2 & 56 \\
\hline-2 & 4 & 2 & 55 \\
\hline 8 & 12 & 20 & 50 \\
\hline 0 & 4 & 4 & 48 \\
\hline 8 & 10 & 18 & 47 \\
\hline 2 & 4 & 6 & 36 \\
\hline 0 & 0 & 0 & 35 \\
\hline 0 & 2 & 2 & 34 \\
\hline 4 & 0 & 4 & 22 \\
\hline 0 & 0 & 0 & 17 \\
\hline 0 & 4 & 4 & 15 \\
\hline 2 & 0 & 2 & 14 \\
\hline-4 & -8 & -12 & 13 \\
\hline 0 & 0 & 0 & 8 \\
\hline 0 & 0 & 0 & 2 \\
\hline 0 & 0 & 0 & 0 \\
\hline 0 & 0 & 0 & 0 \\
\hline 0 & 0 & 0 & 0 \\
\hline 1.69 & 2.08 & 3.77 & 5.63 \\
\hline
\end{tabular}

FIGURE 5 | Reported adoption of MM exercises is correlated with health improvement over the prior year. Reported health change over the duration of the study is shown in graphical form, with green the most positive and red the most negative. Physical health change and affective health change are shown separately and summed for total health score. Exercise adoption score is also shown, and the data are ordered according to this score. Averages are shown at the bottom. Table $\mathbf{4}$ below shows correlational analysis.

spirometrically detectable changes may require longer or more intense practice. The MM intervention training contained no form of resistance training or aerobic exercise and the underlying physiological mechanisms of these changes remain uncertain. We have speculated that they are due to changes in the autonomic nervous system. In the current study, autonomic function, as measured by COMPASS 31, showed improvement in the MM interventional group, while scores in the control group indicted poorer autonomic function (as was reported in Phase I) although this did not reach statistical significance.

The MAIA measures the degree of awareness that an individual has of their body feelings. This self-report instrument has ten sub-scores that test various aspects of interoceptive awareness. Tests of subjects in the MM training group indicated a substantial and significant increase in MAIA score. A capacity for self-regulation is hypothesized to relate to interoceptive
TABLE 4 | Exercise adoption is positively correlated with health improvement.

\begin{tabular}{lcccc}
\hline & Pearson's $\boldsymbol{R}$ & $\boldsymbol{R}$ squared & $\boldsymbol{P}$-value & $\begin{array}{c}\text { Significance } \\
\text { level }\end{array}$ \\
\hline $\begin{array}{l}\text { Exercise adoption to } \\
\text { total health change }\end{array}$ & 0.5822 & 0.34 & 0.003 & $P<0.005$ \\
$\begin{array}{l}\text { Exercise adoption to } \\
\text { physical health change }\end{array}$ & 0.6163 & 0.38 & 0.001 & $P<0.005$ \\
$\begin{array}{l}\text { Exercise adoption to } \\
\text { affective health change }\end{array}$ & 0.4445 & 0.20 & 0.03 & $P<0.05$ \\
$\begin{array}{l}\text { Physical health change } \\
\text { to affective health } \\
\text { change }\end{array}$ & 0.7257 & 0.53 & 0.000 & $P<0.001$ \\
\end{tabular}

Statistical analysis of the results of SM questionnaire 2 are shown. Pearson's $R$ indicates the strength of the correlation; R-squared indicates the percent of variance accounted for by the interaction of the variables, significance level is also given. Highly significant moderate positive correlations are shown between reported degree of adoption of the MM exercises, and reported changes in physical and affective health over the prior year including participation in the study.

awareness $(48,73)$. This capacity includes the ability of the anterior cingulate gyrus and the prefrontal cortex to modulate arousal in the hypothalamus and limbic system, central components of the ANS $(48,73,74)$. The hypothesis that the $\mathrm{MM}$ intervention acted in part by improving autonomic functioning via increased top-down control, is supported by the significant $24 \%$ increase in the MAIA score. The ability of the autonomic nervous system to receive afferent information about the physiological state of the body, primarily via the vagus nerve, is known to be crucial to autonomic regulation of organ function, which plays a significant role in COPD (75). Conscious interoception, the ability to be consciously aware of the body sensations which bring information about the visceral state of the body, has been shown to play a vital role in self-regulation and emotional self-control $(47,49,50,76)$. This strongly impacts the ability to take voluntary, conscious self-regulatory actions to cope with stress in a more resilient way. We note that, in this study, not only did the overall MAIA score improve significantly, but also the sub-score pertaining to self-regulation carried the majority of the improvement (Although all the sub-scores improved in comparison to the control group, only the self-regulation score reached statistical significance). These results suggest that improved interoceptive capacity may be part of the mechanism whereby MM improves the functioning of the ANS.

Kinesthetic interoception also plays a prominent role in the body's maintenance of mechanically efficient posture and movement, which are strongly emphasized in the MM training. Improved body mechanics and postural balance is also a plausible explanation for the dramatic improvement in 6MWT performance, which we have observed in both Phase I (38) and II of this study.

Several of the secondary outcome measures changed in the same direction as in the Phase I study, but without reaching statistical significance. In each case the change in the intervention group was in the direction of improved health, and in the control group in the direction of worse health or minimal change. These include hs-CRP, COMPASS 31, Zung Anxiety, and resting heart rate. In this cohort of women, average age 68 , the expectation 


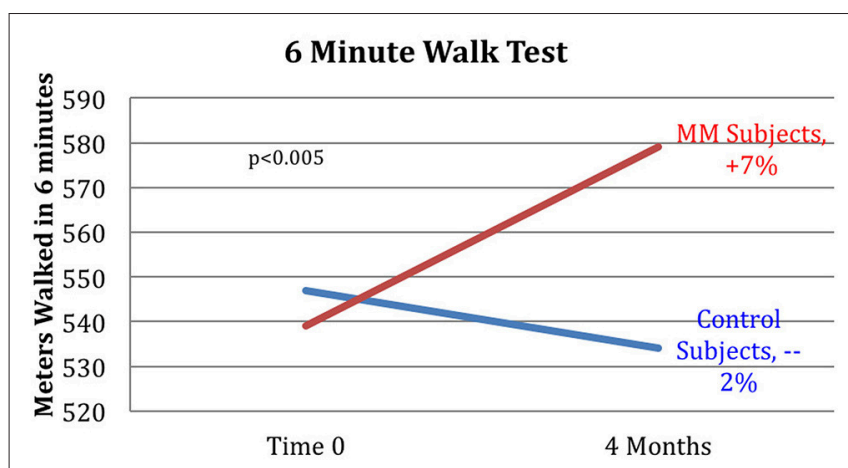

FIGURE 6 | Improved 6MWT score for MM group vs. control group. Subjects in the MM group averaged a 7\% increase in distance covered in the 6MWT over the 4 months between pre- and post-testing. Control HE subjects averaged a $-2 \%$ change during the same time frame. ANOVA yields a $p<$ 0.005 .

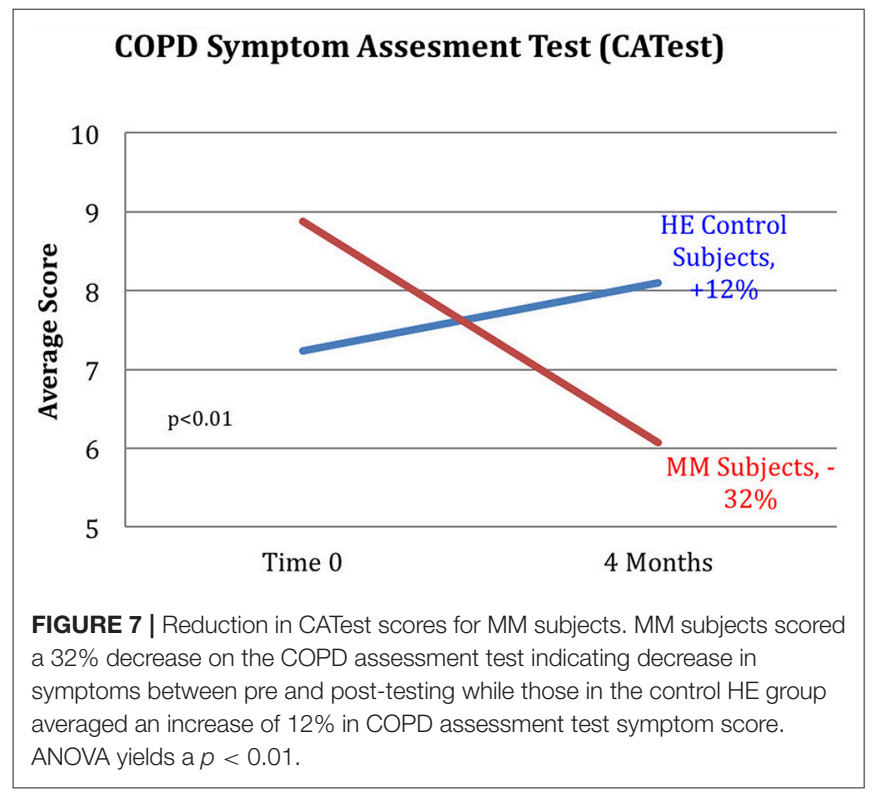

is of gradual decline in health. Despite being in better health to begin with, the control group demonstrated the expected decline in almost all measures: a $2 \%$ reduction in the 6MWT, no change in resting heart rate, a $12 \%$ adverse change in the CATest score, a $7 \%$ increase in measure of autonomic dysfunction by COMPASS 31 , a slight reduction in PEF, and $-1 \%$ change in the MAIA. Both groups had reduced hs-CRP levels, but the control group had substantially less reduction than the MM group (-6 vs. $-29 \%$ ). Similarly, both had reduced anxiety, but the MM group showed over twice as much reduction as the control group ( -4 vs. $-10 \%)$.

Despite the lack of statistical significance of some of these results, these outcomes suggest a pattern in the intervention group of generally increasing health, where one would expect an age-related decline, as seen in the control group. These results call for further research with further refinement of instructional methods and a larger cohort.

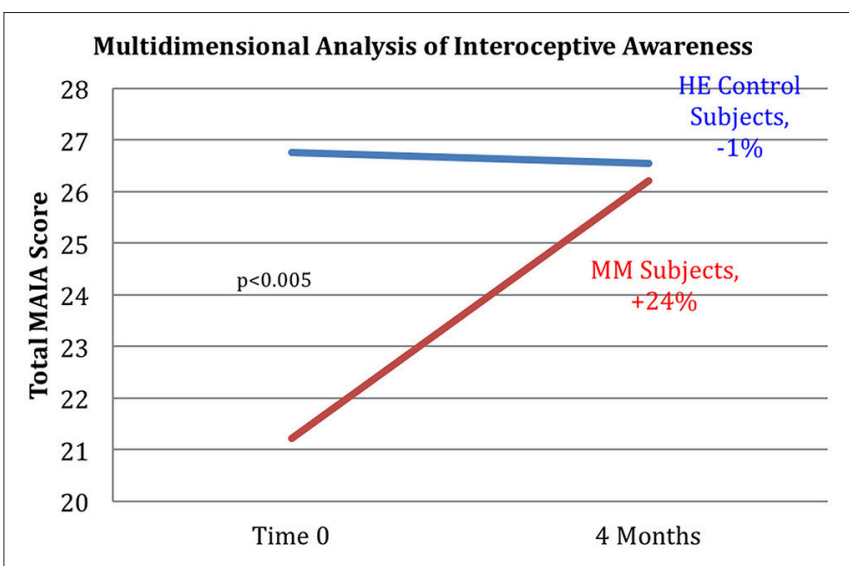

FIGURE 8 | Improved interoception in MM group as shown by MAIA score. Subjects in the MM group averaged a $24 \%$ increase in MAIA overall interoceptive awareness score over the 4 months between pre and post-testing. Control subjects averaged a $1 \%$ decrease during the same time frame. ANOVA analysis yields a $p<0.005$.

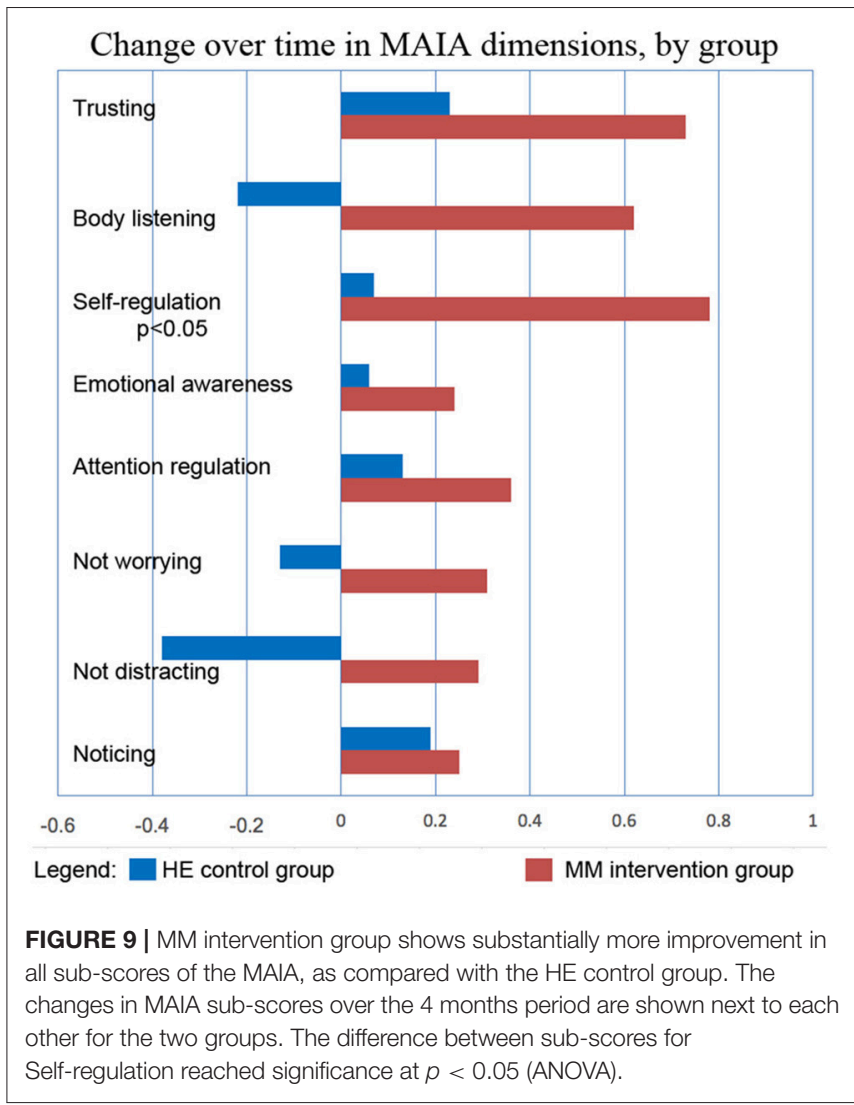

Interestingly, blood levels of DHEAS increased substantially in the MM group as compared with the control group; a $42 \%$ increase vs. a $10 \%$ decrease, at a significance level of $p=0.057$ which closely approached defined significance. In the Phase I study, DHEAS increased by $37 \%$, but the result did not reach significance. DHEA is an important precursor of a number of steroid hormones in the body. It declines significantly 


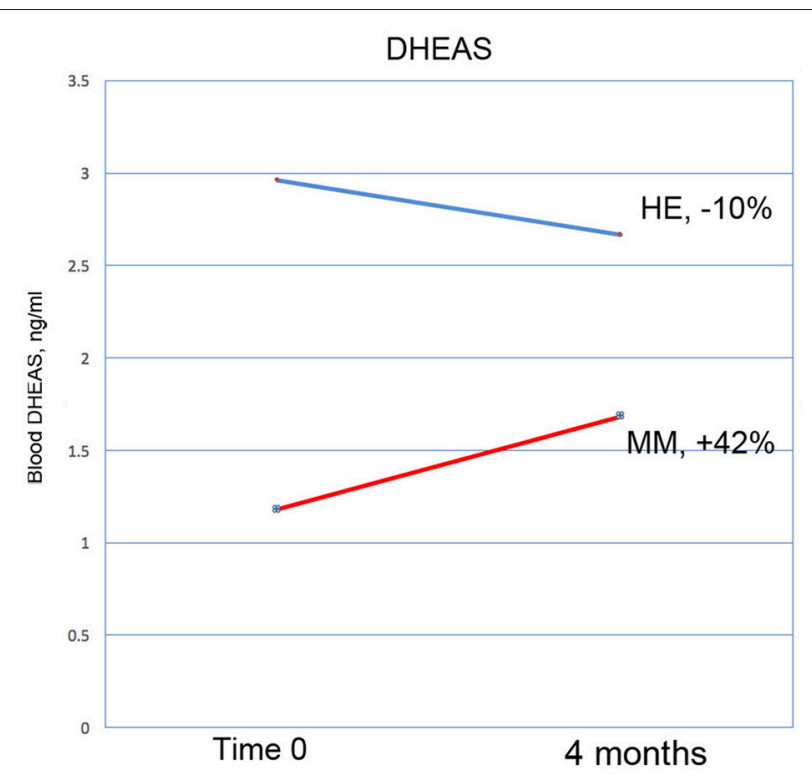

FIGURE 10 | DHEAS increased by $42 \%$ in the MM intervention group over the 3 months of the study, compared with a drop of $10 \%$ in the HE control group. This result nearly reaches significance at $p=0.0566$ (ANOVA).

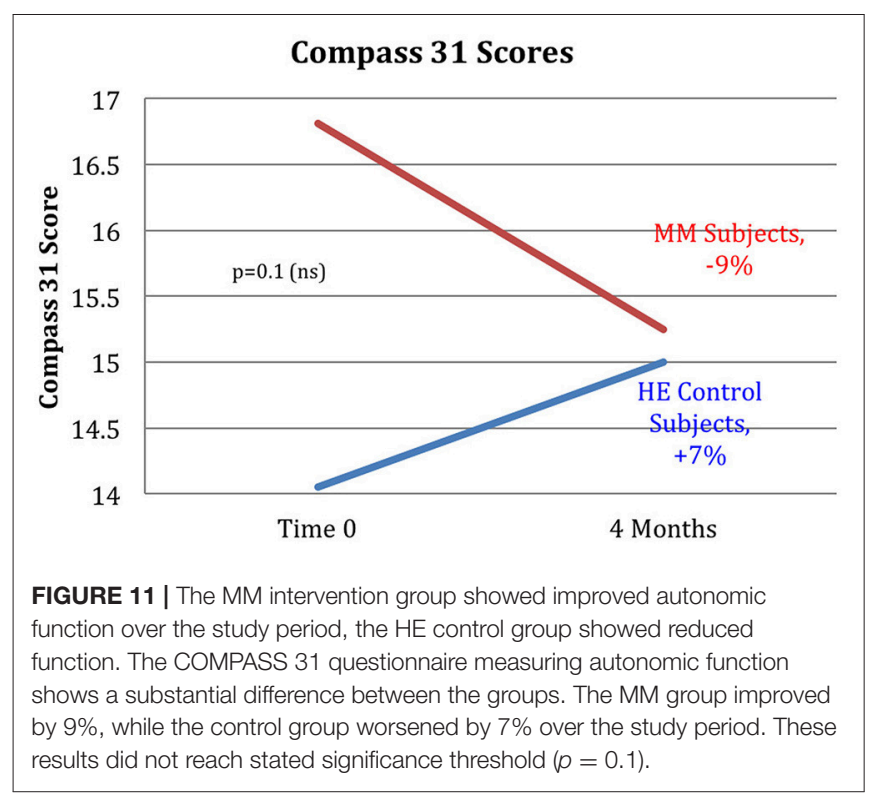

with age, and low levels are associated with an increase in neurodegenerative conditions, possibly due to its affinity with neurotrophin receptors (77). There is evidence that it increases brain levels of neuro-protective substances, such as nerve growth factor and brain-derived neurotrophic factor (78). In a rat model of Alzheimer's disease it demonstrates neuro-protective function (79), and may be involved in the mechanisms of depression (80). Although there is evidence that DHEA supplementation has no significant benefits in healthy people (81), it can be of benefit in certain disorders [for example $(82,83)]$. Meditation $(84)$ and exercise have been shown to increase DHEA levels; for a review, see (85). We suggest that in future similar studies DHEAS should be considered as a useful objective marker of improved health in this kind of intervention.

\section{Survey Monkey Questionnaires}

Survey Monkey questionnaire 1 demonstrated that the participants had a substantially positive view of the study, with some criticisms of the videos for being too long and not sufficiently engaging. Their descriptions of their experiences with the practices were highly positive; in view of the MAIA results, it is interesting that participants strongly affirmed their perception of an increased ability to handle stress (self-regulation) and almost universally expressed a desire to continue with a similar study.

Survey Monkey questionnaire 2 showed a significant $(p<$ 0.005 ) and moderate correlation (Pearson's $R=0.58$ ) between the degree of adoption of the MM exercises, and reported health changes over the prior year, which included the duration of the study. Given the number of factors which can influence health changes over the course of a year, we regard this correlation as an important result supporting the overall positive impact of the MM training. We eliminated from the analysis participants who experienced a major health event over the year, such as hip or knee replacement surgery, on the basis that such an event would not be influenced by the study and would introduce irrelevant confounding factors. It seems unlikely that this would unduly distort our results. We do however recognize that causal effects can go both ways: participants in better health might have been more likely to adhere to the MM practices. Therefore, we regard this result as supportive but not definitive.

\section{Nicotine and the Autonomic Nervous System}

The harmful effects of cigarette smoke on the lungs and cardiovascular system are well-known. The short-term effects of CS and nicotine on the ANS are less widely known but well-studied: inhaled cigarette smoke causes immediate effects on the autonomic nervous system, including increased heart rate due to catecholamine secretion, temporary mood elevation probably due to dopamine and DHEA, and stimulation of the hypothalamic-pituitary-adrenal (HPA) axis, which triggers the release of the "stress hormone" cortisol (86). Chronic smokers have elevated levels of cortisol and disturbances in the diurnal cortisol rhythm (87). It is known that chronic stress impairs recovery from fear-inducing situations, which contributes to the likelihood of developing PTSD or other anxiety disorders. Recent work strongly suggests that cigarette smoke can cause long-term disruption of the autonomic nervous system, likely as a result of the effects mentioned above on the HPA axis.

Animal studies have shown that nicotine caused extended fear responses, enhanced fear conditioning (22), delayed extinction of fear memories $(23,24)$, and disrupted safety learning $(17,25)$. In humans, children exposed to SHCS had higher rates of major depressive disorder and attention-deficit/hyperactivity disorder (20). A clear association has been observed between smoking and anxiety disorders, including PTSD (21). In emergency 
workers, smoking after exposure to a disaster was associated with increased PTSD symptoms; the authors suggest that smokingrelated dysregulation of the hypothalamic-pituitary-adrenal axis contributes to increased PTSD symptoms (18).

The concept that nicotine exposure has long-term as well as short term effects on the autonomic nervous system, is distinct in concept from earlier literature. Previously the literature primarily documented the use of nicotine as a form of self-medication in individuals diagnosed with various affective disorders. The more recent accumulation of evidence for the negative effects of nicotine on the ability to recover from chronic stress and trauma, strongly support an intervention directed at the ANS of FA subjects to support recovery from the long-term health effects of SHCS exposure that occurred while working in a highstress environment. Further, we think it likely that the disruption of ANS function consequent to SHCS exposure may exacerbate other morbidities associated with CS exposure, such as COPD and cardiovascular issues.

\section{Generalizability}

This study addressed a specific population, flight attendants with workplace-related second-hand cigarette smoke exposure for more than 5 years. This, and the requirement to attend pre- and post-testing, limited the pool of eligible subjects to functionally mobile, current and former female FA over the age of 49. The generalizability of these results to the non-FA population-males, younger people, and those with more severe pathology-remains to be established; however, given the results of other MM studies with different populations, it appears likely that similar results would be obtained.

In comparing our study with other MM studies, we note that the intervention we developed differs from other MM practices in that it emphasizes integrating the principles of MM practice with daily life, rather than setting aside specific times for practice as is universally done in other studies (88). We believe that our approach improves effectiveness, compliance and accessibility, which are major hurdles for MM studies with a general population.

We have previously argued that precise and complete descriptions of MM interventions, used in research, need to be documented to support further studies of the impact of the intervention (46). These descriptions are also needed to form hypotheses relating to mechanism. Details of this intervention and the videos that we used to teach the MM protocol are available as Supplementary Materials. As with much clinical research, compliance remains an ongoing concern. We plan

\section{REFERENCES}

1. Crawford WA, Holcomb LC. Environmental tobacco smoke (ETS) in airliners-a health hazard evaluation. Aviat Space Environ Med. (1991) 62:580-6.

2. Grajewski B, Nguyen MM, Whelan EA, Cole RJ, Hein MJ. Measuring and identifying large-study metrics for circadian rhythm disruption in female flight attendants. Scand J Work Environ Health (2003) 29:337-46. doi: $10.5271 /$ sjweh.740 future studies to determine ways to increase compliance and effectiveness of MM training.

\section{Potential Confounders}

As noted above, baseline characteristics of the control group showed substantially better overall health than the intervention group. We do not believe this is likely to have distorted our results; if anything, we would speculate that participants in worse health would have been less likely to comply with the practices.

\section{Future Directions}

Future research needs to include further testing of refined training materials, modified methods of delivery, and the use of a larger cohort, to confirm the results from this study. We are currently exploring methods for making the videos more succinct and engaging, with the use of special effects, illustrative footage, images, sound effects, and music. Testing in other populations is also warranted but may also require specific modifications of the training for different populations. We believe that the specific style of intervention tested here offers considerable potential advantages over other forms, in that it can be effectively learned from videos, requires minimal or no separate practice time, and can be integrated with all the activities of daily life thus greatly increasing potential impact.

\section{AUTHOR CONTRIBUTIONS}

PP, MC-G, and SF were responsible for project planning and execution. $\mathrm{DZ}$ provided testing resources. $\mathrm{AB}$ and $\mathrm{PH}$ provided video resources, video editing and project planning. TG contributed substantially to the manuscript. PP, MC-G, and CG were responsible for writing and major editing of manuscript. All provided editorial review.

\section{ACKNOWLEDGMENTS}

We would like to thank the participants in the study, and acknowledge the invaluable help of Drs Jay Leiter and Phyllis Stein for consultation. We thank the Flight Attendant Medical Research Institute (FAMRI) and the American Academy of Paediatrics for support that made this research possible.

\section{SUPPLEMENTARY MATERIAL}

The Supplementary Material for this article can be found online at: https://vimeo.com/album/5491789 of flight attendants. Tobacco Control (2004) 13(Suppl. 1):i8-19. doi: 10.1136/tc.2003.003111

4. Sutton PM, Vergara X, Beckman J, Nicas M, Das R. Pesticide illness among flight attendants due to aircraft disinsection. Am J Ind Med. (2007) 50:345-56. doi: 10.1002/ajim.20452

5. Arjomandi M, Haight T, Redberg R, Gold WM. Pulmonary function abnormalities in never smoking flight attendants exposed to secondhand tobacco smoke in the aircraft cabin. J Occup Environ Med Am Coll 
Occup Environ Med. (2009) 51:639-46. doi: 10.1097/JOM.0b013e3181 a7f048

6. Arjomandi M, Haight T, Sadeghi N, Redberg R, Gold WM. Reduced exercise tolerance and pulmonary capillary recruitment with remote secondhand smoke exposure. PLOS ONE (2012) 7:e34393. doi: 10.1371/journal.pone. 0034393

7. McNeely E, Gale S, Tager I, Kincl L, Bradley J, Coull B, et al. The self-reported health of US flight attendants compared to the general population. Environ Health (2014) 13:13. doi: 10.1186/1476-069X-13-13

8. Whelan EA, Lawson CC, Grajewski B, Petersen MR, Pinkerton LE, Ward EM, et al. Prevalence of respiratory symptoms among female flight attendants and teachers. Occup Environ Med. (2003) 60:929-34. doi: 10.1136/oem.60.12.929

9. Pinkerton LE, Waters MA, Hein MJ, Zivkovich Z, Schubauer-Berigan MK, Grajewski B. Cause-specific mortality among a cohort of U.S. flight attendants. Am J Ind Med. (2012) 55:25-36. doi: 10.1002/ajim.21011

10. Czura CJ. Autonomic neural regulation of immunity. J Intern Med. (2005) 257:156-66. doi: 10.1111/j.1365-2796.2004.01442.x

11. Shrikrishna D, Hopkinson NS. Chronic obstructive pulmonary disease: consequences beyond the lung. Clin Med. (2012) 12:71-4. doi: 10.7861/clinmedicine.12-1-71

12. Vestbo J, Hurd SS, Agustí AG, Jones PW, Vogelmeier C, Anzueto A, et al. Global strategy for the diagnosis, management, and prevention of chronic obstructive pulmonary disease: GOLD executive summary. Am J Respir Crit Care Med. (2013) 187:347-65. doi: 10.1164/rccm.201204-0596PP

13. Rennard SI, Drummond MB. Early chronic obstructive pulmonary disease: definition, assessment, and prevention. Lancet (2015) 385:1778-88. doi: 10.1016/S0140-6736(15)60647-X

14. Han MK, Agusti A, Calverley PM, Celli BR, Criner G, Curtis JL, et al. Chronic obstructive pulmonary disease phenotypes: the future of COPD. Am J Respir Crit Care Med. (2010) 182:598-604. doi: 10.1164/rccm.200912-1843CC

15. Abrams TE, Blevins A, Vander Weg MW. Chronic obstructive lung disease and posttraumatic stress disorder: current perspectives. Int J Chronic Obstructive Pulm Dis. (2015) 10:2219-33. doi: 10.2147/COPD.S71449

16. Kutlu MG, Gould TJ. Nicotine modulation of fear memories and anxiety: implications for learning and anxiety disorders. Biochem Pharmacol. (2015) 97:498-511. doi: 10.1016/j.bcp.2015.07.029

17. Kutlu MG, Oliver C, Gould TJ. The effects of acute nicotine on contextual safety discrimination. J Psychopharmacol. (2014) 28:1064-70. doi: 10.1177/0269881114552743

18. van der Velden PG, Kleber RJ, Koenen KC. Smoking predicts posttraumatic stress symptoms among rescue workers: a prospective study of ambulance personnel involved in the Enschede fireworks disaster. Drug Alcohol Depend. (2008) 94:267-71. doi: 10.1016/j.drugalcdep.2007.11.001

19. Flight Attendant Certification. InFO 08106, 3/21/2008: Flight Attendant Certificate of Demonstrated Proficiency. USDoT; FAA (2004). Available online at: http://www.faa.gov/other_visit/aviation_industry/airline_operators/ airline_safety/info

20. Bandiera FC, Richardson AK, Lee DJ, He J-P, Merikangas KR. Secondhand smoke exposure and mental health among children and adolescents. Archives Pediatr Adolesc Med. (2011) 165:332-8. doi: 10.1001/archpediatrics.2011.30

21. Thorndike FP, Wernicke R, Pearlman MY, Haaga DA. Nicotine dependence, PTSD symptoms, and depression proneness among male and female smokers. Addict Behav. (2006) 31:223-31. doi: 10.1016/j.addbeh.2005.04.023

22. Davis JA, Porter J, Gould TJ. Nicotine enhances both foreground and background contextual fear conditioning. Neuroscience Lett. (2006) 394:202-5. doi: 10.1016/j.neulet.2005.10.026

23. Kutlu MG, Gould TJ. Acute nicotine delays extinction of contextual fear in mice. Behav Brain Res. (2014) 263:133-7. doi: 10.1016/j.bbr.2014.01.031

24. Kutlu MG, Holliday E, Gould TJ. High-affinity $\alpha 4 \beta 2$ nicotinic receptors mediate the impairing effects of acute nicotine on contextual fear extinction. Neurobiol Learn Memory (2016) 128:17-22. doi: 10.1016/j.nlm.2015.11.021

25. Connor DA, Kutlu MG, Gould TJ. Nicotine disrupts safety learning by enhancing fear associated with a safety cue via the dorsal hippocampus. J Psychopharmacol. (2017) 31:934-44. doi: 10.1177/0269881117695861

26. Johnson JA, Stewart JM, Howell MH. Chinese Medical Qigong Therapy: a Comprehensive Clinical Guide. Pacific Grove, CA: International Institute of Medical Qigong (2000). 1086 pp.

27. Dong X, Bergren S. Qigong among older adults: a global review. Clin Res. (2016) 2:120-44. doi: 10.15761/CRT.1000130
28. Lee JB. Values of health qigong as elderly exercise. 한국발육발달학회지. (2015) 23:77-82.

29. Cohen K. The Way of Qigong. Los Angeles, CA: Wellspring/Ballantine (1999).

30. Larkey L, Jahnke R, Etnier J, Gonzalez J. Meditative movement as a category of exercise: implications for research. J Phys Act Health (2009) 6:230-8. doi: 10.1123/jpah.6.2.230

31. Chan AW, Lee A, Lee DT, Suen LK, Tam WW, Chair S, et al. The sustaining effects of Tai chi Qigong on physiological health for COPD patients: a randomized controlled trial. Complement Ther Med. (2013) 21:585-94. doi: 10.1016/j.ctim.2013.09.008

32. Liu X-D, Jin H-Z, Ng BH-P, Gu Y-H, Wu Y-C, Lu G. Therapeutic effects of Qigong in patients with COPD: a randomized controlled trial. Hong Kong $J$ Occup Ther. (2012) 22:38-46. doi: 10.1016/j.hkjot.2012.06.002

33. Ng BH, Tsang HW, Jones AY, So CT, Mok TY. Functional and psychosocial effects of health qigong in patients with COPD: a randomized controlled trial. J Altern Complement Med. (2011) 17:243-51. doi: 10.1089/acm.2010.0215

34. Chan AWK, Lee A, Suen LKP, Tam WWS. Tai chi Qigong improves lung functions and activity tolerance in COPD clients: a single blind, randomized controlled trial. Complement Ther Med. (2011) 19:3-11. doi: 10.1016/j.ctim.2010.12.007

35. Ng BH, Tsang HW, Ng BF, So C-t. Traditional Chinese exercises for pulmonary rehabilitation: evidence from a systematic review. J Cardiopulm Rehabil Preven. (2014) 34:367-77. doi: 10.1097/HCR.0000000000000062

36. Xu Y, Wang J, Li H, Zhu X, Wang G. Efficacy of integrative respiratory rehabilitation training in exercise ability and quality of life of patients with chronic obstructive pulmonary disease in stable phase: a randomized controlled trial. Zhong Xi Yi Jie He Xue Bao (2010) 8:432-7. doi: 10.3736/jcim20100506

37. Jahnke R, Larkey L, Rogers C, Etnier J, Lin F. A comprehensive review of health benefits of qigong and tai chi. Am J Health Promot. (2010) 24:1-25. doi: 10.4278/ajhp.081013-LIT-248

38. Payne P, Fiering S, Leiter J, Zava D, Crane-Godreau M. Effectiveness of a Novel Qigong meditative movement practice for impaired health in flight attendants exposed to second-hand cigarette smoke. Front Hum Neurosci. (2017) 11:67. doi: 10.3389/fnhum.2017.00067

39. Lee MS, Kang C-W, Lim H-J, Lee M-S. Effects of Qi-training on anxiety and plasma concentrations of cortisol, ACTH, and aldosterone: a randomized placebo-controlled pilot study. Stress Health (2004) 20:243-8. doi: $10.1002 /$ smi. 1023

40. Lee MS, Huh HJ, Kim BG, Ryu H, Lee H-S, Kim J-M, et al. Effects of Qi-training on heart rate variability. Am J Chinese Med. (2002) 30:463-70. doi: 10.1142/S0192415X02000491

41. Lee MS, Kim HJ, Moon SR. Qigong reduced blood pressure and catecholamine levels of patients with essential hypertension. Int J Neurosci. (2003) 113:1691701. doi: 10.1080/00207450390245306

42. Lee MS, Lee MS, Choi E-S, Chung H-T. Effects of Qigong on blood pressure, blood pressure determinants and ventilatory function in middleaged patients with essential hypertension. Am J Chinese Med. (2003) 31:48997. doi: 10.1142/S0192415X03001120

43. Sun FL, Yan YA. Effects of various qigong breathing pattern on variability of heart rate. Zhongguo Zhong Xi Yi Jie He Za Zhi (1992) 12:527-30.

44. Chan RR, Larson JL. Meditation interventions for chronic disease populations a systematic review. J Holistic Nurs. (2015) 33:351-65. doi: $10.1177 / 0898010115570363$

45. Wang X, Pi Y, Chen B, Chen P, Liu Y, Wang R, et al. Effect of traditional Chinese exercise on the quality of life and depression for chronic diseases: a meta-analysis of randomised trials. Sci Rep. (2015) 5:15913. doi: 10.1038/srep15913

46. Payne P, Crane-Godreau MA. Meditative movement for depression and anxiety. Front Psychiatry (2013) 4:71. doi: 10.3389/fpsyt.2013.00071

47. Damasio A. Feelings of emotion and the self. Anna N Y Acad Sci. (2003) 1001:253-61. doi: 10.1196/annals.1279.014

48. Farb N, Daubenmier J, Price CJ, Gard T, Kerr C, Dunn BD, et al. Interoception, contemplative practice, and health. Front psychol. (2015) 6:763. doi: $10.3389 /$ fpsyg. 2015.00763

49. Craig AD. How do you feel? Interoception: the sense of the physiological condition of the body. Nat Rev Neurosci. (2002) 3:655-66. doi: 10.1038/nrn894

50. Critchley HD. Neural mechanisms of autonomic, affective, and cognitive integration. J Comp Neurol. (2005) 493:154-66. doi: 10.1002/cne.20749 
51. Payne P, Zava D, Fiering S, Crane-Godreau M. Meditative movement as a treatment for pulmonary dysfunction in flight attendants exposed to secondhand cigarette smoke: study protocol for a randomized trial. Front Psychiatry (2016) 7:38. doi: 10.3389/fpsyt.2016.00038

52. Payne P, Crane-Godreau M. Supplemental Materials for Study NCT02612389: Consent Form. 1st ed. Cambridge, MA: Harvard Dataverse (2016).

53. Lachin JM, Matts JP, Wei L. Randomization in clinical trials: conclusions and recommendations. Control Clin Trials (1988) 9:365-74. doi: 10.1016/0197-2456(88)90049-9

54. Payne P, Crane-Godreau M. Replication Data for Study NCT02612389: Video Material to Supplement MM Instruction. 1st ed. Cambridge, MA: Harvard Dataverse (2016).

55. Payne P, Crane-Godreau M. Replication Data for Study NCT02612389: PDF Files of Written Material Supplementing the Individual Class Instruction in MM. 1st ed. Cambridge, MA: Harvard Datavers (2016).

56. Payne P, Crane-Godreau M. Replication Data for Study NCT02612389: Audio Files used in MM Instruction. 1st ed. Cambridge, MA: Harvard Dataverse (2016).

57. Ng BH, Tsang HW. Psychophysiological outcomes of health qigong for chronic conditions: a systematic review. Psychophysiology (2009) 46:257-69. doi: 10.1111/j.1469-8986.2008.00763.x

58. Hamilton DM, Haennel RG. Validity and reliability of the 6-minute walk test in a cardiac rehabilitation population. J Cardiopulm Rehabil. (2000) 20:156-64. doi: 10.1097/00008483-200005000-00003

59. Chen LF, Wang CH, Chou PC, Ho SC, Joa WC, Sheng TF, et al. Association between emphysema score, six-minute walk and cardiopulmonary exercise tests in COPD. Open Respir Med J. (2012) 6:104-10. doi: 10.2174/1874306401206010104

60. Chandra D, Wise RA, Kulkarni HS, Benzo RP, Criner G, Make B, et al. Optimizing the six minute walk test as a measure of exercise capacity in COPD. Chest (2012) 142:1545-52. doi: 10.1378/chest.11-2702

61. Carter R, Holiday DB, Nwasuruba C, Stocks J, Grothues C, Tiep B. 6-minute walk work for assessment of functional capacity in patients with COPD. Chest (2003) 123:1408-15. doi: 10.1378/chest.123.5.1408

62. Karadag F, Kirdar S, Karul AB, Ceylan E. The value of C-reactive protein as a marker of systemic inflammation in stable chronic obstructive pulmonary disease. Eur J Inter Med. (2008) 19:104-8. doi: 10.1016/j.ejim.2007. 04.026

63. Kapur S, Kapur S, Zava D. Cardiometabolic risk factors assessed by a finger stick dried blood spot method. J Diabetes Sci Technol. (2008) 2:236-41. doi: $10.1177 / 193229680800200210$

64. Feliz-Rodriguez D, Zudaire S, Carpio C, Martinez E, Gomez-Mendieta A, Santiago A, et al. Evolution of the COPD assessment test score during chronic obstructive pulmonary disease exacerbations: determinants and prognostic value. Can Respir J. (2013) 20:e92-7. doi: 10.1155/2013/ 398120

65. GlaxoSmithKline. CATestOnline: GlaxoSmithKline. Available online at: http:// www.catestonline.org/english/indexEN.htm

66. AmericanThoracicSociety. ATS statement: guidelines for the sixminute walk test. Am J Respir Crit Care Med. (2002) 166:111-7. doi: 10.1164/ajrccm.166.1.at1102

67. Rabe KF, Hurd S, Anzueto A, Barnes PJ, Buist SA, Calverley P, et al. Global strategy for the diagnosis, management, and prevention of chronic obstructive pulmonary disease: GOLD executive summary. Am J Respir Crit Care Med. (2007) 176:532-55. doi: 10.1164/rccm.200703-456SO

68. Sletten DM. COMPASS 31: a refined and abbreviated composite autonomic symptom score. Mayo Clinic (2012) 87:1196-201. doi: 10.1016/j.mayocp.2012.10.013

69. Zung WW. A self-rating depression scale. Archives of general psychiatry. Arch Gen Psychiatry. (1965) 12:63-70. doi: 10.1001/archpsyc.1965.017203100 65008

70. Zung WW. A rating instrument for anxiety disorders. Psychosomatics. (1971) 12:371-9. doi: 10.1016/S0033-3182(71)71479-0

71. Mehling WE, Price C, Daubenmier JJ, Acree M, Bartmess E, Stewart A. The multidimensional assessment of interoceptive awareness (MAIA). PLoS ONE (2012) 7:e48230. doi: 10.1371/journal.pone.0048230

72. McNeely E. Supplemental Materials for Study NCT02612389: Personal Email from Dr. E. McNeely Providing Unpublished Data on Demographics of US Flight Attendants. 1st ed. Cambridge, MA: Harvard Dataverse (2016).
73. Payne P, Levine PA, Crane-Godreau MA. Somatic experiencing: using interoception and proprioception as core elements of trauma therapy. Front Psychol. (2015) 6:93. doi: 10.3389/fpsyg.2015.00093

74. Critchley HD, Mathias CJ, Josephs O, O’Doherty J, Zanini S, Dewar BK, et al. Human cingulate cortex and autonomic control: converging neuroimaging and clinical evidence. Brain (2003) 126:2139-52. doi: 10.1093/brain/awg216

75. Mohammed J, Meeus M, Derom E, Da Silva H, Calders P. Evidence for autonomic function and its influencing factors in subjects with COPD: a systematic review. Respir Care (2015) 60:1841-51. doi: 10.4187/respcare.04174

76. Craig $\mathrm{AD}$. Interoception and Emotion: a Neuroanatomical Perspective. Handbook of Emotion. 3rd ed. New York, NY: Guilford Press (2008).

77. Pediaditakis I, Iliopoulos I, Theologidis I, Delivanoglou N, Margioris AN, Charalampopoulos I, et al. Dehydroepiandrosterone: an ancestral ligand of neurotrophin receptors. Endocrinology (2015) 156:16-23. doi: 10.1210/en.2014-1596

78. Rahmani A, Shoae-Hassani A, Keyhanvar P, Kheradmand D, DarbandiAzar A. Dehydroepiandrosterone stimulates nerve growth factor and brain derived neurotrophic factor in cortical neurons. Adv Pharmacol Sci. (2013) 2013:506191. doi: 10.1155/2013/506191

79. Aly HF, Metwally FM, Ahmed HH. Neuroprotective effects of dehydroepiandrosterone (DHEA) in rat model of Alzheimer's disease. Acta Biochim Pol. (2011) 58:513-20.

80. Wolkowitz OM, Reus VI. Neurotransmitters, neurosteroids and neurotrophins: new models of the pathophysiology and treatment of depression. World J Biol Psychiatry (2003) 4:98-102. doi: 10.1080/15622970310029901

81. Kritz-Silverstein D, Von Mühlen D, Laughlin GA, Bettencourt R. Effects of dehydroepiandrosterone supplementation on cognitive function and quality of life: the DHEA and Well-Ness (DAWN) trial. J Am Geriatrics Soc. (2008) 56:1292-8. doi: 10.1111/j.1532-5415.2008.01768.x

82. Libe R, Barbetta L, Dall'Asta C, Salvaggio F, Gala C, Beck-Peccoz P, et al. Effects of dehydroepiandrosterone (DHEA) supplementation on hormonal, metabolic and behavioral status in patients with hypoadrenalism. J Endocrinol Invest. (2004) 27:736-41. doi: 10.1007/BF03347515

83. Barad D, Brill H, Gleicher N. Update on the use of dehydroepiandrosterone supplementation among women with diminished ovarian function. J Assist Reprod Genet. (2007) 24:629-34. doi: 10.1007/s10815-007-9178-x

84. Glaser JL, Brind JL, Vogelman JH, Eisner MJ, Dillbeck MC, Wallace RK, et al. Elevated serum dehydroepiandrosterone sulfate levels in practitioners of the transcendental meditation (TM) and TM-Sidhi programs. J Behav Med. (1992) 15:327-41. doi: 10.1007/BF00844726

85. Shealy CN. A review of dehydroepiandrosterone (DHEA). Integr Physiol Behav Sci. (1995) 30:308-13. doi: 10.1007/BF02691603

86. Mendelson JH, Sholar MB, Goletiani N, Siegel AJ, Mello NK. Effects of lowand high-nicotine cigarette smoking on mood states and the HPA axis in men. Neuropsychopharmacology (2005) 30:1751-63. doi: 10.1038/sj.npp.1300753

87. Pomerleau OF, Flessland KA, Pomerleau CS, Hariharan M. Controlled dosing of nicotine via an intranasal nicotine aerosol delivery device (INADD). Psychopharmacology (1992) 108:519-26. doi: 10.1007/BF02247431

88. Ng BH, Tsang HW. Establishing a health Qigong protocol for rehabilitation of patients with COPD. Int J Ther Rehabil. (2009) 16:25-33. doi: 10.12968/ijtr.2009.16.1.37937

Conflict of Interest Statement: PP receives financial remuneration in his private practice for teaching material similar to that tested in this study. PP, MC-G, and CG receive compensation as consultants in areas related to the content of this study.

The remaining authors declare that the research was conducted in the absence of any commercial or financial relationships that could be construed as a potential conflict of interest.

Copyright (c) 2018 Payne, Fiering, Zava, Gould, Brown, Hage, Gaudet and CraneGodreau. This is an open-access article distributed under the terms of the Creative Commons Attribution License (CC BY). The use, distribution or reproduction in other forums is permitted, provided the original author(s) and the copyright owner(s) are credited and that the original publication in this journal is cited, in accordance with accepted academic practice. No use, distribution or reproduction is permitted which does not comply with these terms. 


\section{ACRONYMS}

\begin{tabular}{|c|c|}
\hline 6MWT & Six minute walk test \\
\hline$A D$ & Autonomic dysfunction \\
\hline ANS & Autonomic nervous system \\
\hline $\mathrm{BP}$ & Blood pressure \\
\hline CS & Cigarette smoke \\
\hline COPD & Chronic obstructive pulmonary disease \\
\hline hs-CRP & High sensitivity C-reactive protein \\
\hline DHEAS & Dehydroepiadrosterone sulfate \\
\hline DVD & Digital video disc \\
\hline FA & Flight attendants \\
\hline FAMRI & Flight attendant medical research institute \\
\hline FEF & Forced expiratory flow \\
\hline FEV1 & Forced expiratory volume one \\
\hline FVC & Forced vital capacity \\
\hline GOLD & Global initiative on Obstructive Lung Disease \\
\hline $\mathrm{HR}$ & Heart rate \\
\hline MAIA & Multidimensional assessment of interoceptive awareness \\
\hline MM & Meditative movement \\
\hline PEF & Peak Expiratory Flow \\
\hline $\mathrm{Pl}$ & Principal investigator \\
\hline RCT & Randomized controlled trial \\
\hline SHCS & Second-hand cigarette smoke \\
\hline
\end{tabular}

A standard test for assessing functional ability, the distance walked in 6 min

Portion of the nervous system controlling those physiological functions outside normal voluntary control.

Chronic disease involving obstruction of the small airways and alveolar tissue disruption Bio-marker of systemic inflammation

A steroid hormone precursor

Standard vehicle for presenting video

The foremost organization promoting research into medical problems affecting flight attendants.

Spirometric measurement, flow of air during forced exhalation

A measure of lung function: the maximum volume of air breathed out in a forcible exhalation in $1 \mathrm{~s}$

A measure of lung function: the total volume of air breathed out in a complete forcible exhalation

A research and information group that is the principal global authority on the nature and treatment of COPD

A questionnaire designed to evaluate several dimensions of interoceptive awareness A newly identified form of exercise characterized by a meditative state of mind, deep relaxation, movement, and attention to the breathing. Qigong and Yoga are the best known examples

The maximum rate of flow achieved in a forced expiration

The premier form of research study in which participants are randomly assigned to control or intervention group for the purpose of objective assessment of an intervention

Cigarette smoke inhaled by someone other than the smoker; ambient smoke not inhaled directly through the cigarette 